\title{
Do Psychological Well-Being characteristics vary with Birth Order?
}

\author{
Geeta Sharma and Srimathi N L \\ University of Mysore
}

\begin{abstract}
The effect of Birth Order on Personality has remained a debated research topic with studies favouring and not favouring the possible impacts. While there has been substantial research separately on Birth Order and Psychological Well-Being (PWB) scarcely can we find studies relating Birth Orders with various sub-scales of PWB.The present study was thus conducted amongst students of Mysore $(n=273)$ to investigate the whether the Birth Order characteristics vary with the sub-scales of Ryff's PWB scale. Significant differences were found among all Birth Orders. Research implications and significance of the study conclude the article.
\end{abstract}

Key words: Birth Order, Psychological Well-Being, Autonomy, Environmental Mastery, Positive Relations, Personal Growth, Purpose in Life, Self-Acceptance.

\section{Introduction}

For every individual, family is the first contact to the outside world and home is where the personality is given a firm foundation. Thus, family environment and upbringing play a pivotal role in shaping the individual and shaping his personality traits. The study of Personality has been an intriguing and controversial subject in Psychology for decades.

Among the many other theories of personality, Adler's Individual Psychology, especially Birth Order has been widely acclaimed yet debated. Adler, like Freud acknowledged the importance of the first five years of life in influencing people's future development (Reichenberg, 2011). However Alder's views were less deterministic. He believed that biological and physiological factors provided probabilities for future growth but that "the self, with creative power as part of its inner nature, is the important intervening variable" (Ansbacher \& Ansbacher, 1956). Adler paid considerable attention to other influences in development including family constellation and birth order. He believed that through an examination of family constellation, we can understand people's lifestyles. A person's family constellation includes the composition of the family, each person's roles, the reciprocal transactions that a person has, during the early formative years with siblings and parents. The child is not a passive recipient of these transactions; rather, children influence how parents and siblings respond to them. Each child comes to play a role in the family that is determined by the interactions and transactions within that family. (Reichenberg, 2011)

\section{Characters believed to be associated with each Birth Order}

\begin{tabular}{|c|c|c|}
\hline S1. No. & Birth Order & Characters believed to be associated \\
\hline 1 & First Borns & $\begin{array}{l}\text { Tend to be most intelligent and achieving of the five groups. Their verbal skills are especially strong. } \\
\text { First borns, who initially grow up in a family of adults, tend to be dependable, well-organized and } \\
\text { responsible. While first borns are the only child in the family, they tend to be the center of attention and } \\
\text { sometimes are spoiled. However, when siblings are born, oldest children tend to feel dethroned and may } \\
\text { feel threatened, angry, fearful and jealous in response to losing their special role as only child. Dealing } \\
\text { successfully with the birth of a sibling can help first-borns become more filial and self-confident. }\end{array}$ \\
\hline 2 & Middle borns & $\begin{array}{l}\text { Some middle children feel squeezed between older children who have already found their place and } \\
\text { younger children who seem to receive more love and attention. Middle children sometimes have } \\
\text { difficulty finding a way to become special and can become discouraged, viewing themselves as unloved } \\
\text { and neglected. This pattern is usually less evident in large families where two or more children share the } \\
\text { role of middle child but is particularly likely in families with only three children. With encouragement } \\
\text { and positive training, however, middle children often become well-adjusted, friendly, creative and } \\
\text { ambitious, prizing their individual strengths }\end{array}$ \\
\hline 3 & Last Borns & $\begin{array}{l}\text { Encounter three main pitfalls: they maybe pampered and spoiled by the rest of the family, they may feel } \\
\text { a need to go at top speed at all times just to keep up with their older siblings and they become } \\
\text { discouraged about competing with their brothers and sisters. They often become adventurous, easy- } \\
\text { going, empathetic, sociable and innovative. They typically pursue interests that all their own to avoid } \\
\text { competition with siblings. Their lost likely ally is the oldest who also has feelings of being different. }\end{array}$ \\
\hline 4 & $\begin{array}{l}\text { Single } \\
\text { children }\end{array}$ & $\begin{array}{l}\text { Have much in common with first born and last born children. They seek achievement like first borns and } \\
\text { usually enjoy being the center of attention like the youngest. They may become pampered and spoiled, } \\
\text { focusing only on their needs, but may also integrate the achievement orientation of the first born with } \\
\text { the creativity of later born children. Because all other family members are adults, these children mature } \\
\text { early and learn to co-operate and deal well with adults. However, if the parents are insecure, they may } \\
\text { adopt parental worries and insecurities. }\end{array}$ \\
\hline
\end{tabular}


(Reichenberg, 2011)

\section{Studies favouring Birth Order-Personality relationship}

\section{Literature review}

A compilation of over 200 published articles was done by the Authors- Eckstein, Aycock, Sperber, McDonald, Wiesner, Watts and Ginsburg in the form of a Journal Article. Here, lifestyle characteristics associated with birth order were tabulated to provide a clear picture of results. Examples of typical characteristics associated with persons of specific birth-order positions include high success and achievement for first-born children, high need for achievement for only children, high sociability for middle children, and high social interest for youngest children. (Daniel Eckstein)

Hartshorne J K, Hartshorne N S and Hartshorne TS tested for birth order effects in a theory-neutral manner, using a long-term, stable behavior as the dependent measure (the formation of close relationships) rather than personality assessments. Two Surveys were done: one on Undergraduates and another through Internet. According to their study, Birth Order did seem to be a reliable factor for determining the formation of long-term relationships, with people of similar Birth Orders forming close platonic and romantic relationships with other people of the same Birth Order. (Hartshorne, Salem-Hartshorne, \& Hartshorne)

Warren J R through his article "Birth Order and Social Behaviour" brings about the possible effects of Birth Order in Education, Family Life and Occupational life. He also links the possibility of Birth Oder to conformity or dependence, delinquency, alcoholism, and schizophrenia as well as college attendance and affiliative behavior through various other works. He brings about a physiological understanding to the relation of Birth Order to various Psychological Disorders. (Warren, 1966)

A study by Zajonc and Markus carried out on over 400000 people of 19 years of age, describe a confluence model that explains the effects of birth order and family size on intelligence. Their study shows that intellectual development within the family context is conceived of as depending on the cumulative effects of the intellectual environment, which consists primarily of the siblings' and parents' intelligence. (Zajonc \& Markus, 1975)

The Authors Adams and Bert N review the theories, findings, problems, and possibilities of birth-order research. They opine that assumptions of most birth-order studies are incorporated by intrauterine or physiological, only-child uniqueness, dethronement, anxious or relaxed parent, sibling influence, and economic theories. The 2 most consistent findings in the literature are that: (a) greater educational attainment, including college attendance, appears among first-borns (including only children); and (b) firstborns are more affiliative and dependent than later-borns. Problems include cohort and demographic difficulties, needed controls and specifications, the restrictiveness of early socialization theories, and researcher-induced bias in experimental studies. (Adams, 1972)

Healey and Ellis investigated differences between firstborn and second born siblings on major dimensions of personality through two surveys: 1) by finding the effects of birth order on conscientiousness and openness to experience differences between siblings in a university sample and 2) by finding the effects of birth order on the Big 5 personality traits between siblings in an older sample. In both studies, birth-order differences in accordance with Sulloway's model tended to be larger within pairs of sisters than within pairs of brothers. By focusing specifically on contrasts between first-born and second-born siblings, delimiting age gaps between siblings, and restricting the analyses to sibling pairs that were born and raised in the same family environment without the confounding influence of half siblings and stepsiblings, the research design provided a strong test of Sulloway's theoretical model. This refined within-family design has proved to be an adequate method for uncovering birth-order personality effects. (Healey, 2007)

Paulhus, Trapnell and Chen investigated Birth Order effects on Personality and Achievement in four studies: 1) Preliminary data through California students 2) Salience study among British Columbia students 3) Student take-home package 4) Vancouver Adult take-home package. They used the Big Five Factor questionnaire and Achievement Motivation Questionnaire. Only first-borns and last-borns were considered for the study. The studies confirmed the Birth Order differences predicted by the family-niche model of personality development (Sulloway, 1996) and the confluence model of intellectual development (Zajonc \& Markus, 1975). Extroversion was the weakest factor found, while Conscientiousness, Agreeableness, Liberalism and Rebellion indicated clear differences. It was also found that First Borns were intellectually more achieving than last-borns. (Paulhus, Trapnell, \& Chen, 1999)

Saroglou and Fiasse conducted a study where 122 young adults from three-sibling families completed the Neuroticism, Extroversion, Openness Psychological Inventory Rating Scale (NEO-PI-R) and gave information on religion and school performance. Only Middle Borns and Elder-Borns were considered. Mother's evaluation of personality was also assessed. Middle-borns seemed to represent the "rebellious" (laterborn) sibling in Sulloway's theory (Sulloway, 1996) in comparison to their siblings, they were less conscientious, less religious, and lower in school performance, as well as more impulsive and open to fantasy, whereas last- borns were the most agreeable and warm. In most cases, effects were similar in self and mother- 
evaluation. Finally, mother ratings validated self-reported personality correlates of religion (Conscientiousness, Agreeableness, low impulsiveness and low excitement seeking) and spirituality. (Saroglou \& Fiasse, 2003)

$\mathrm{Bu}$ in his paper "Sibling Configurations, Educational Aspiration and Attainment" advances the state of knowledge that first-born children enjoy a distinct advantage over their later-born counter-parts in terms of educational attainment in two ways: First, he analyses the role of young people's aspirations, estimating the effects of sibling configurations on adolescents' educational aspirations, and the importance of these aspirations on later attainment. Second, he employs multi-level modelling techniques, using household-based data which include information on multiple children living in the same families. The paper finds that firstborn children have higher aspirations, and that these aspirations play a significant role in determining later levels of attainment. He also demonstrates a significant positive effect of age spacing on educational attainment. (Bu, 2014 )

Salmon C did a survey on undergraduates ( $\mathrm{n}=245$ ), where they completed a questionnaire relating to their attitudes toward friends and family as well as some aspects of mating behavior. In her study, Birth order did have a significant impact in several areas. Middle-borns expressed more positive views toward friends and less positive opinions of family in general. They were less inclined to help family in need than firstborns or lastborns. Mating strategies also appeared to be influenced by birth order, most notably in the area of infidelity, with middle-borns being the least likely birth order to cheat on a sexual partner. (Salmon, 2003)

\section{Studies not in favour of Birth Order-Personality Relationship}

A study was conducted among 10,317 men and women who graduated from Wisconsin high schools in 1957 and of their randomly selected brothers and sisters. This was a longitudinal study which took 35 years by Hauser, Kuo and Cartmill. The data was collected through Mental Ability tests, school performance, while the siblings's data was also parallelly collected. Several years later the same participants were interviewed again through telephone, which dealt with questions regarding Emotional, Psychological and Physical Well-Being. The final results however, showed no significant effect of Birth Order on Personality of the siblings. (Hauser, Kuo, \& Cartmill, 1999)

The Authors Schooler and Carmi reviewed birth order effects, which considered previously reported and unreported data and recently hypothesized biases arising from long-term population trends. It revealed (a) almost no reliable evidence for birth order effects among males living in the United States in the middle 1960s, and (b) only a marginal increase in such evidence when restrictions on time, place, and sex are removed. This conclusion is based on data from both psychiatric and normal populations examined by comparing (a) the prevalence of particular birth ranks in relevant populations, (b) characteristics of individuals of different birth ranks, and (c) parents' reports of their treatment of children of different birth ranks. (Schooler, 1972)

Black, Deverux and Salvanes used a rich data set on the entire population of Norway over an extended period of time and examined the effects of family size and birth order on the educational attainment of children. They found a negative correlation between family size and children's education, but when indicators for birth order or use twin births as an instrument were included, family size effects became negligible. In addition, higher birth order seemed to have a significant and large negative effect on children's education. They also studied adult earnings, employment, and teenage childbearing and find strong evidence for birth order effects with these outcomes, particularly among women. These findings suggested the need to revisit economic models of fertility and child "production," focusing not only on differences across families but differences within families as well. (Black \& Deverux)

Jefferson, Herbst and McCrae conducted 3 studies to find out the association between Birth Order and Personality Traits through Self-Report findings and Observer Ratings. After the studies, the Authors felt that if birth order were a powerful influence on personality the failure of self-report inventories to detect it would imply a serious critique of self-report methods. They also felt that there is vastly more evidence supporting the validity of self-reports than there is supporting effects of birth order. The Authors feel that Sulloways' extensive historical research found evidence for strong effects of birth order on behavior during times of radical scientific revolution, but the effects of birth order on personality traits are modest at best. The Authors conclude by saying that birth order and personality are largely independent predictors of creative lives. (Jefferson, Herbst, \& McCrae, 1998)

\section{The present research}

Despite the various studies on Birth Order, there have been fewer studies on the impact of Birth Order on the various scales of Psychological Well-Being. The study here, is thus centered on finding out which characteristics are likely to be found on the various Birth Orders using the Psychological Well-Being Scale by Ryff. 


\section{Participants \\ III. Method \\ 273 students of Mysore, out of which 117 Under-Graduate and 156 Post-Graduate students participated in the study. The age group was between 18-43 years and data was collected from various Under Graduate (UG) and Post Graduate Colleges (PG) in Mysore. Students from various backgrounds were administered the questionnaires. For analytic purposes the respondents were divided into four Birth Order groups namely: First Borns ( $\mathrm{n}=89)$, Middle Borns $(\mathrm{n}=47)$, Last Borns $(\mathrm{n}=95)$ and Single children $(\mathrm{n}=45)$.}

\section{Tool used}

The Psychological Well-Being Scale (Middle Version) consisting of 54 items was used, along with Kannada version as well.

\section{Data collection}

Pilot study: To check the feasibility of the scales Pilot Study was first conducted $(n=30)$. Since many of the students were from Rural background (Kannada being the mother tongue) the respondents had difficulty answering in English. Many also felt that the longer version of the Ryff's Psychological Well-Being Scale (84 items) was tedious to answer and boredom set in after the 3rd sub-scale.

Bearing these in mind, both Kannada and English versions of the Scale were used. The Middle Version of Ryff's Scale (54-item) was used for the main study.

Main study: Ryff's Psychological Well-Being Scale (54 items). Data was collected from various PostGraduate and Under-Graduate colleges in Mysore.

The participants were briefed about the importance of their participation for the study. It was also conveyed that their data would be used solely for the study and not for any other purpose. After a rapport was established, appropriate instructions were given to them and they were asked to fill in the questionnaires along with personal information. Sufficient time was given and Kannada versions of the forms were given to anyone who was not comfortable in English. Clarifications were done for all those who answered the questionnaires then and there itself. It was clearly instructed not to leave any answer blank.

\section{Analysis of results}

\section{Results and Discussion}

Once the scoring was done (bearing the negative scoring of Psychological Well-Being Scale), the obtained data was entered into SPSS (version 16). One sample t- test was used for interpretation of the data. The results are discussed in detail.

\section{First Borns and scores of PWB scales}

Significant differences were found among all the sub-scales of the PWB questionnaire $(\mathrm{p}<0.05)$. According to the statistical analysis, First Borns seem to have Personal Growth as the highest characteristic, Autonomy $2^{\text {nd }}$ highest, Environmental Mastery $3^{\text {rd }}$ highest, Positive Relations as the $4^{\text {th }}$ highest. Self acceptance is the $2^{\text {nd }}$ lowest, while Purpose in Life is the least seen characteristic.

(Table 1 approximately here)

(Table 2 approximately here)

(Graph 1 approximately here)

\section{Middle Borns and PWB}

Significant differences were found among all the sub-scales of the PWB questionnaire. It was found that Personal Growth was highest, Autonomy was the $2^{\text {nd }}$ highest, Environmental Mastery was $3^{\text {rd }}$ highest, Positive relations were $4^{\text {th }}$ highest. Self Acceptance was $2^{\text {nd }}$ lowest, while Purpose In Life seemed to be the least.

(Table 3 approximately here)

(Table 4 approximately here)

(Graph 2 approximately here)

\section{Last Borns and PWB}

One-Way ANOVA was used to find out whether there are any significant differences in the various sub-scales of PWB among Last Borns. According to the statistical analysis, Environmental Mastery is seen highest. Personal Growth, Positive Relations, Autonomy have the $2^{\text {nd }}, 3^{\text {rd }}, 4^{\text {th }}$ highest scores. Self-acceptance is $2^{\text {nd }}$ lowest, while Purpose in Life is least seen. 
(Table 5 approximately here)

(Table 6 approximately here)

(Graph 3 approximately here)

\section{Single children and PWB}

Significant differences were found among all the sub-scales of the PWB scale. According to the statistical analysis, Self-acceptance is highest in Single children. $2^{\text {nd }}$ highest is Purpose in Life, while Environmental Mastery and Personal Growth are $3^{\text {rd }}$ and $4^{\text {th }}$ respectively. Positive Relations is the $2^{\text {nd }}$ lowest, while Autonomy is the lowest.

(Table 7 approximately here)

(Table 8 approximately here)

(Graph 4 approximately here)

\section{Summary of results}

It was found that Personal Growth was highest in First Borns and Middle Borns. Environmental Mastery was seen highest in Last Borns, while Self-acceptance was most seen in Single children. Purpose in Life was least seen in First, Middle and Last Borns. Autonomy was least seen in Single children.

\section{Discussion}

The present study was done to find out the likely characteristics prevalent in the various Birth Orders as per Ryff's Psychological Well-being Scale. Significant differences were found among all four Birth Orders in the six sub-scales of PWB scale.

First Borns and Middle Borns seem to show similar characteristics, since Personal Growth was seen highest. This may be due to the early maturity and understanding of the world that they attain soon after their younger sibling or siblings are born. This is similar to studies where it was found that First Borns had higher Achievement Motivation, Aspiration, Vocation and Academic Achievement. Many First Borns and Middle Borns take on responsibility of taking care of their family, especially younger siblings, automatically. This pressurizes them to do well in academics and ultimately support their family, especially if the family is in a financial crisis. Thus, according to the analysis of results, First Borns and Middle Borns are more likely to have goals in life and a sense of directedness. They may also have feelings of continued development, see themselves as growing and expanding,realize his or her potential, see an improvement in self and behavior over time, or change in ways that reflect more self-knowledge and effectiveness. (Seifert, 2005)

Environmental Mastery was seen highest in last Borns, according to the statistical analysis. Hence, they may have a sense of mastery and competence in managing the environment, control complex array of external activities, make effective use of surrounding opportunities, or have the ability to choose or create contexts suitable to personal needs and values. (Seifert, 2005). This is probably due to the increased freedom and opportunities provided to the Last Borns, who are usually the most loved and cared for. Usually elder sibling or elder siblings provide support and guidance to the individual, thus making him a better decision maker with managerial skills.

The statistical analysis indicate higher self-acceptance in Single children, thus meaning that they possesses a positive attitude toward themselves, acknowledge and accept multiple aspects of self and feel positive about past life (Seifert, 2005). Single children mature quickly, since they have higher sense of worldly affairs, due to their constant interaction with adults. Since they have no siblings, they are not compared constantly to anyone in the nuclear family and tend to develop a unique personality. Though they maybe compared to cousins or neighbors, it will not have a profound effect as being compared to siblings.

The statistical analysis indicate that First, Middle and Last Borns had least Purpose in Life. This indicates that they lack a sense of meaning in life, have few goals or aims, lack sense of direction, do not see purpose of past life and have no outlook or beliefs that give life meaning (Seifert, 2005).

Autonomy was least seen in Single children. This indicates that they are concerned about the expectations and evaluations of others, rely on judgments of others to make important decisions and conform to social pressures to think and act in certain ways. (Seifert, 2005)

\section{Research implications}

The present study gives an indication of the possible differences in Psychological Well-Being (PWB) among the various Birth Orders. Few studies have taken place keeping in mind the PWB characteristics of various Birth Orders, hence the present study provides a better understanding of the various PWB characteristics among First, Middle, Last Borns and Single Children. This is backed up by Statistical findings and analysis. 
Taking into consideration related studies, the present study will provide a comprehensive understanding of the likely characteristics of each Birth Order.

\section{Limitations of the study}

Students of various Colleges in Mysore were randomly requested to participate in the survey, thus making the study based on inclusive-exclusive criterion. Since results of the same siblings could not be compared, it could not be investigated whether Psychological Well-being characteristics differ significantly between siblings.

Parental upbringing, Type of Family, gender and age gap between siblings, cultural and societal upbringing also has a very strong impact on the Personality and Lifestyle characteristics of an individual. However, they were not taken into consideration for the study.

Though the participants came from various backgrounds, they were limited to Mysore city only. Hence, the results of the study cannot be generalized to all cultures.

\section{Concluding remarks}

Notwithstanding its limitations the study gives some indications as to which Birth Order is more likely to have which PWB characteristic. Along with the physical Birth Order, the psychological Birth Order of an individual along with aspects such as Parental upbringing, Type of Family, Gender and gap between siblings, cultural and societal upbringing could be considered for Psychotherapy and Counselling to have a profound effect on the individual. This will provide a holistic approach to understanding the possible effect of Birth Order on Personality and Lifestyle characteristics.

\section{Acknowledgement}

We would like to express our gratitude to the all the staff of Department of studies, Mysore University and to SBRR Mahajana's First Grade College, Mysore for greatly assisting Data Collection of Under-Graduate students.

\section{References}

[1]. Adams, B. N. (1972). Birth order : a critical review. Sociometry: A Journal Of Research in Social Psychology,Vol 35(3), 411-431.

[2]. Ansbacher, \& Ansbacher. (1956). The Individual Psychology of Alfed Adler: a systematic presentation in selections from his writings. Oxford England: Basic Books.

[3]. Black, S. E., \& Deverux, P. J. (2004) The More the Merrier? The Effect of Family Size and Birth Order on Children's Education. The Quarterly Journal of Economics, Vol 120 (2), 669-700

[4]. Bu, F. (2014 ). Sibling Configurations, Educational Aspiration and Attainment . Colchester: Institute for Social and Economic Research.

[5]. Daniel Eckstein, K. J. (2010). A Review of 200 Birth-Order Studies: Lifestyle Characteristics. Individual Psychology, Vol 66 (4), $408-430$

[6]. Hartshorne, J. K., Salem-Hartshorne, N, \& Hartshorne, T. S. (2009). Birth order effects in the formation of long-term relationships. Individual Psychology, Vol 65(2), 156-195.

[7]. Hauser, R. M., Kuo, H.-H. D., \& Cartmill, R. (1999). Birth Order and Personality among Adult Siblings: Are There Any Effects?

[8]. Healey, M. D. (2007). Birth Order, conscientiousness and openess to experience-Tests of the family-niche model of ppersonality using a within family methodololgy. Evolution and Human Behavior, Vol 28, $55-59$

[9]. Jefferson, J. T., Herbst, J., \& McCrae, R. (1998). Associations between Birth Order and Personality Traits: Evidence from SelfReports and Observer Ratings. Journal Of Research in Personality, Vol 32 (4), 98-509.

[10]. Paulhus, D. L., Trapnell, P. D., \& Chen, D. (1999). Birth Order effects Personality and achievement within families. Psychological Science, Vol 10 (6), 482-488.

[11]. Reichenberg, L. S. (2011). Theories of Counselling and Psychotherapy. New Delhi: PHI Learning Private Limited.

[12]. Salmon, C. (2003). Birth Order and relationships. Human Nature, Vol 14 (1), 73-88.

[13]. Saroglou, V, \& Fiasse, L. (2003). Birth order, personality, and religion: a study among young adults from a three-sibling family. Personality and Individual Differences, Vol 35, 19-29.

[14]. Schooler, C. (1972). Birth Order effects: Not here not now. Psychological Bulletin, Vol 78 (3), 161-175.

[15]. Seifert, T. A. (2005). The Ryff Scales of Psychological Well-Being. Retrieved from http://www.liberalarts.wabash.edu/ryff-scales/.

[16]. Sulloway, F. J. (1996). Born to rebel: Birth order, family dynamics and creative lies. New York: Pantheon.

[17]. Warren, J. R. (1966). Birth Order and Social Behaviour. Psychological Bulletin, Vol 65 (1), 38-49.

[18]. Zajonc, R. B., \& Markus, G. B. (1975). Birth order and intellectual development. Psychological Review, Vol 82 (1), 74-88. 
List of tables

Table 1: One-sample statistics for the various sub-scales of PWB on First Borns

One-Sample Statistics

\begin{tabular}{|l|r|r|r|r|}
\hline & $\mathrm{N}$ & \multicolumn{1}{|c|}{ Mean } & Std. Deviation & \multicolumn{1}{c|}{ Std. Error Mean } \\
\hline Autonomy & 85 & 35.15 & 6.962 & .755 \\
Environmental Mastery & 85 & 37.19 & 7.926 & .860 \\
PersonalGrowth & 85 & 39.59 & 7.663 & .831 \\
PositiveRelations & 85 & 37.85 & 8.177 & .887 \\
PurposeInLife & 85 & 38.42 & 9.061 & .983 \\
Self Acceptance & 85 & 38.47 & 8.588 & .931 \\
\hline
\end{tabular}

Table 2: One-sample t-test for First Borns and various sub-scales of PWB One-Sample Test

\begin{tabular}{|c|c|c|c|c|c|c|}
\hline & \multirow[b]{2}{*}{$\mathrm{t}$} & \multirow[b]{2}{*}{ df } & \multirow[b]{2}{*}{ Sig. (2-tailed) } & \multirow[b]{2}{*}{ Mean Difference } & \multicolumn{2}{|c|}{$\begin{array}{l}95 \% \text { Confidence Interval of } \\
\text { the Difference }\end{array}$} \\
\hline & & & & & Lower & Upper \\
\hline Autonomy & 46.554 & 84 & .000 & 35.153 & 33.65 & 36.65 \\
\hline $\begin{array}{l}\text { Environmental } \\
\text { Mastery }\end{array}$ & 43.258 & 84 & .000 & 37.188 & 35.48 & 38.90 \\
\hline PersonalGrowth & 47.630 & 84 & .000 & 39.588 & 37.94 & 41.24 \\
\hline PositiveRelations & 42.671 & 84 & .000 & 37.847 & 36.08 & 39.61 \\
\hline PurposeInLife & 39.095 & 84 & .000 & 38.424 & 36.47 & 40.38 \\
\hline Self Acceptance & 41.300 & 84 & .000 & 38.471 & 36.62 & 40.32 \\
\hline
\end{tabular}

Table 3: One-sample statistics for Middle Borns and the various scales of PWB One-Sample Statistics

\begin{tabular}{|l|r|r|r|r|}
\hline & $\mathrm{N}$ & Mean & Std. Deviation & Std. Error Mean \\
\hline Autonomy & 47 & 33.62 & 8.821 & 1.287 \\
Environmental Mastery & 47 & 34.23 & 9.508 & 1.387 \\
PersonalGrowth & 47 & 35.89 & 9.222 & 1.345 \\
PositiveRelations & 47 & 33.23 & 9.370 & 1.367 \\
PurposeInLife & 47 & 36.79 & 11.104 & 1.620 \\
SelfAcceptance & 47 & 36.83 & 10.927 & 1.594 \\
\hline
\end{tabular}

Table 4: One-sample t-test for Middle Borns One-Sample Test

\begin{tabular}{|c|c|c|c|c|c|c|}
\hline & \multicolumn{6}{|c|}{ Test Value $=0$} \\
\hline & \multirow[b]{2}{*}{$\mathrm{t}$} & \multirow[b]{2}{*}{ df } & \multirow[b]{2}{*}{ Sig. (2-tailed) } & \multirow[b]{2}{*}{ Mean Difference } & \multicolumn{2}{|c|}{$\begin{array}{l}\text { 95\% Confidence Interval of the } \\
\text { Difference }\end{array}$} \\
\hline & & & & & Lower & Upper \\
\hline Autonomy & 26.128 & 46 & .000 & 33.617 & 31.03 & 36.21 \\
\hline $\begin{array}{l}\text { Environmental } \\
\text { Mastery }\end{array}$ & 24.684 & 46 & .000 & 34.234 & 31.44 & 37.03 \\
\hline PersonalGrowth & 26.682 & 46 & .000 & 35.894 & 33.19 & 38.60 \\
\hline $\begin{array}{c}\text { PositiveRelation } \\
\text { s }\end{array}$ & 24.317 & 46 & .000 & 33.234 & 30.48 & 35.99 \\
\hline PurposeInLife & 22.712 & 46 & .000 & 36.787 & 33.53 & 40.05 \\
\hline SelfAcceptance & 23.107 & 46 & .000 & 36.830 & 33.62 & 40.04 \\
\hline
\end{tabular}


Table 5: One-sample statistics for Last Borns

\begin{tabular}{|c|c|c|c|c|}
\hline & $\mathrm{N}$ & Mean & Std. Deviation & Std. Error Mean \\
\hline Autonomy & 95 & 39.19 & 8.353 & .857 \\
\hline EnvMastery & 95 & 41.31 & 8.085 & .829 \\
\hline PersonalGrowth & 95 & 42.82 & 8.659 & .888 \\
\hline PositiveRelations & 95 & 40.98 & 8.669 & .889 \\
\hline PurposeInlife & 95 & 41.71 & 9.620 & .987 \\
\hline Self Acceptance & 95 & 40.71 & 8.814 & .904 \\
\hline
\end{tabular}

Table 6: One Sample t-test for Last Borns

One-Sample Test

\begin{tabular}{|c|c|c|c|c|c|c|}
\hline & \multicolumn{6}{|c|}{ Test Value $=0$} \\
\hline & \multirow[b]{2}{*}{$\mathrm{t}$} & \multirow[b]{2}{*}{ Df } & \multirow[b]{2}{*}{ Sig. (2-tailed) } & \multirow[b]{2}{*}{ Mean Difference } & \multicolumn{2}{|c|}{$\begin{array}{l}95 \% \text { Confidence Interval of the } \\
\text { Difference }\end{array}$} \\
\hline & & & & & Lower & Upper \\
\hline Autonomy & 45.729 & 94 & .000 & 39.189 & 37.49 & 40.89 \\
\hline $\begin{array}{l}\text { Environmental } \\
\text { Mastery }\end{array}$ & 49.797 & 94 & .000 & 41.305 & 39.66 & 42.95 \\
\hline Personal Growth & 48.200 & 94 & .000 & 42.821 & 41.06 & 44.58 \\
\hline PositiveRelations & 46.075 & 94 & .000 & 40.979 & 39.21 & 42.74 \\
\hline PurposeInlife & 42.254 & 94 & .000 & 41.705 & 39.75 & 43.67 \\
\hline Self-Acceptance & 45.016 & 94 & .000 & 40.705 & 38.91 & 42.50 \\
\hline
\end{tabular}

Table 7: One-Sample statistics for Single children

\begin{tabular}{|l|r|r|r|r|}
\hline & $\mathrm{N}$ & Mean & Std. Deviation & Std. Error Mean \\
\hline Autonomy & 38 & 33.11 & 8.465 & 1.373 \\
Environmental Mastery & & 38 & 35.63 & 7.261 \\
PersonalGrowth & 38 & 35.87 & 8.234 & 1.178 \\
PositiveRelations & 38 & 36.11 & 8.868 & 1.336 \\
PurposeInLife & 38 & 37.71 & 7.587 & 1.439 \\
Self-Acceptance & 38 & 35.87 & 6.995 & 1.231 \\
\hline
\end{tabular}

Table 8: One-sample t-test for Single Children

One-Sample Test

\begin{tabular}{|c|c|c|c|c|c|c|}
\hline & \multicolumn{6}{|c|}{ Test Value $=0$} \\
\hline & \multirow[b]{2}{*}{$\mathrm{t}$} & \multirow[b]{2}{*}{ df } & \multirow[b]{2}{*}{ Sig. (2-tailed) } & \multirow[b]{2}{*}{ Mean Difference } & \multicolumn{2}{|c|}{$\begin{array}{l}\text { 95\% Confidence Interval of the } \\
\text { Difference }\end{array}$} \\
\hline & & & & & Lower & Upper \\
\hline Autonomy & 24.107 & 37 & .000 & 33.105 & 30.32 & 35.89 \\
\hline $\begin{array}{l}\text { Environmental } \\
\text { Mastery }\end{array}$ & 30.249 & 37 & .000 & 35.632 & 33.24 & 38.02 \\
\hline Personal Growth & 26.854 & 37 & .000 & 35.868 & 33.16 & 38.57 \\
\hline Positive Relations & 25.099 & 37 & .000 & 36.105 & 33.19 & 39.02 \\
\hline Purpose In Life & 30.640 & 37 & .000 & 37.711 & 35.22 & 40.20 \\
\hline Self-Acceptance & 31.610 & 37 & .000 & 35.868 & 33.57 & 38.17 \\
\hline
\end{tabular}




\section{List of Graphs}

Graph1: t-value of the various sub-scales of PWB on First-Borns

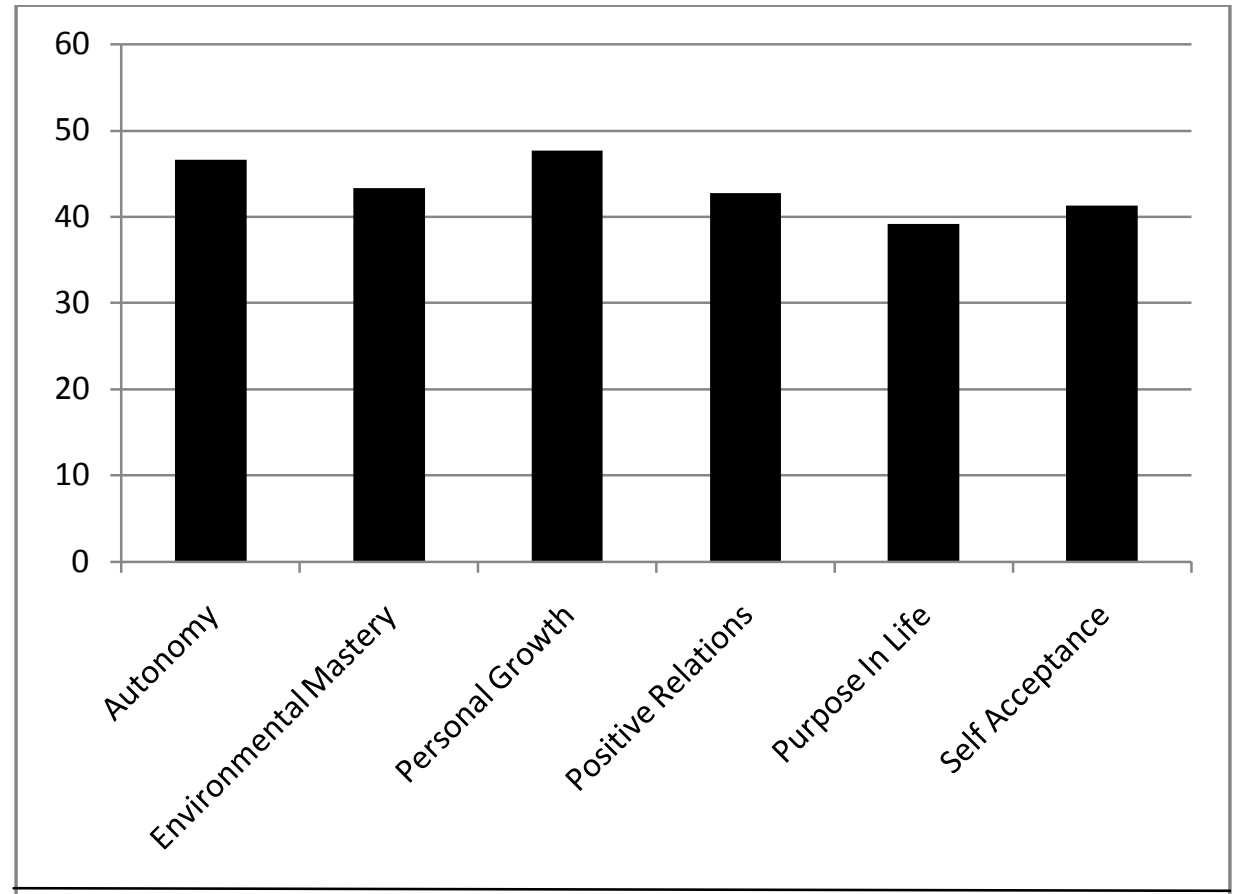

Graph 2: t-value of the various sub-scales of PWB and Middle Borns

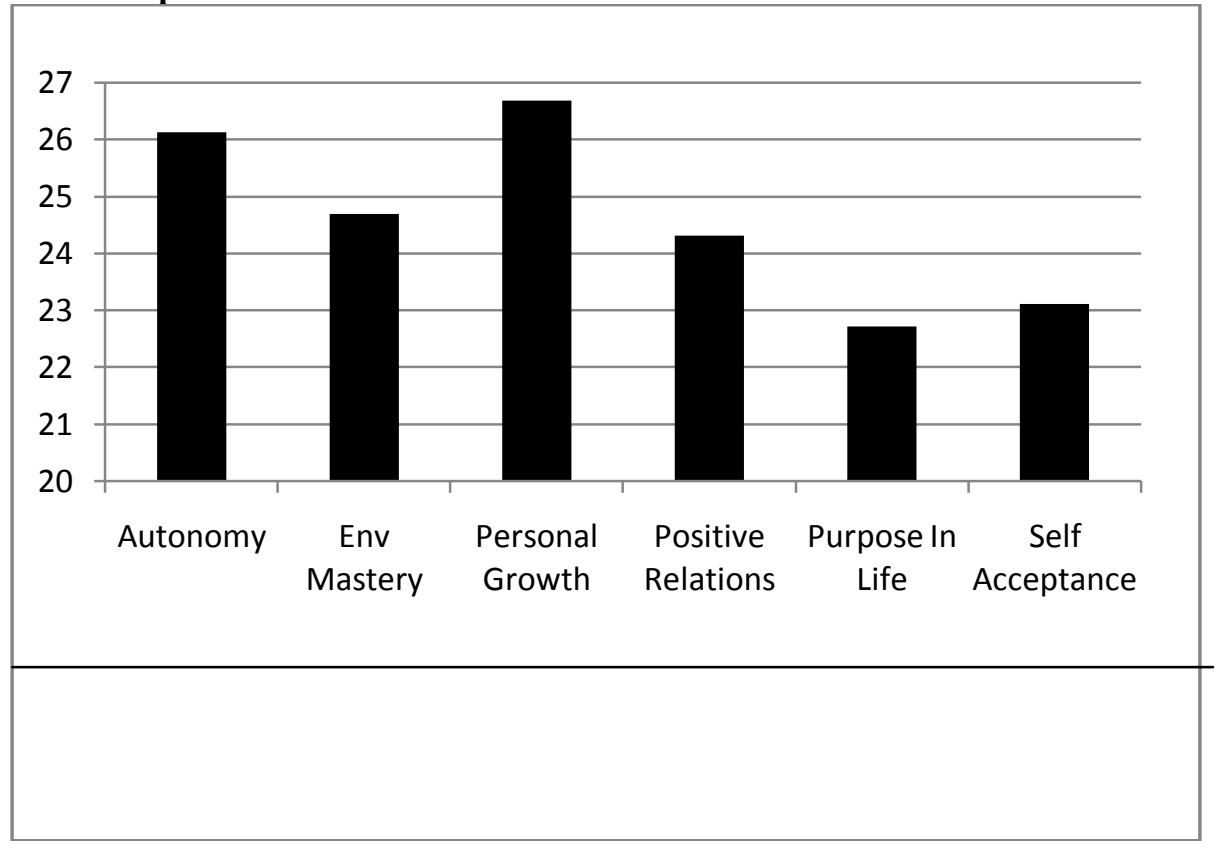




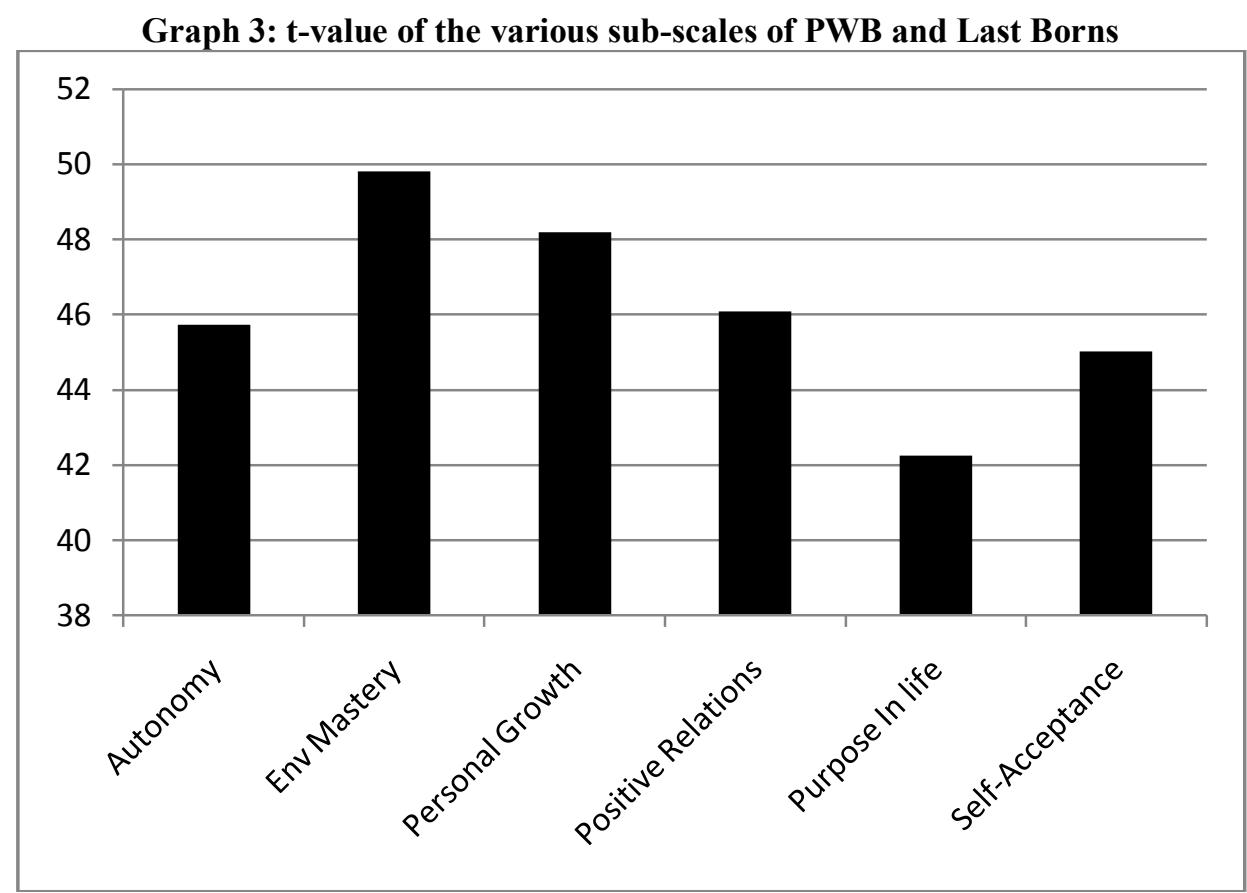

Graph 4: t-value of the various sub-scales of PWB and Single children

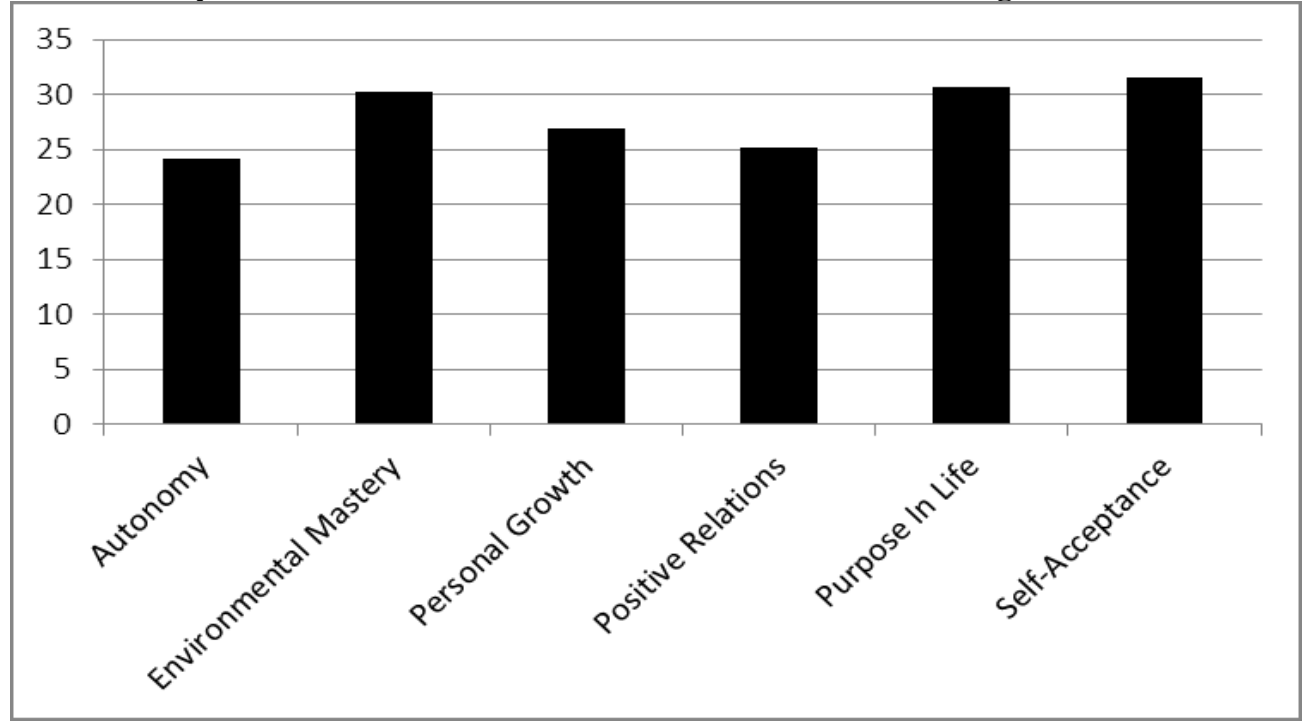

